\title{
ESTRATÉGIAS DE MÃES COM FILHOS PORTADORES DE HIV PARA CONVIVEREM COM A DOENÇA*
}

Marli Teresinha Gimeniz Galvão', Ivana Cristina Vieira de Lima², Gilmara Holanda da Cunhaª ${ }^{3}$ Vanessa da Frota Santos ${ }^{4}$, Maria Isabella Aguiar Mindêllo ${ }^{5}$

\begin{abstract}
RESUMO: Objetivou-se identificar estratégias de mães com filhos portadores de HIV para conviverem com a doença. Trata-se de um estudo qualitativo desenvolvido entre fevereiro e março de 2011 num hospital público de referência no atendimento a indivíduos com HIV e aids em Fortaleza-Ceará. Dez mães portadoras de HIV, com pelo menos um filho com sorologia anti-HIV positiva, participaram de entrevista com roteiro semiestruturado. Os dados foram submetidos à análise temática de conteúdo, produzindo-se cinco categorias: Adoção da religiosidade como fonte de esperança; Avigoramento dos cuidados com a criança e superproteção; Busca do apoio familiar e social; Desenvolvimento da autoculpa; Negação da doença e ocultação do diagnóstico. Os resultados mostram que as mães encontram estratégias positivas e negativas para enfrentarem a doença. A enfermagem pode contribuir na integração dos familiares de portadores de HIV e proporcionar melhor qualidade de vida de acordo com os recursos que estes dispõem para viver. DESCRITORES: HIV; Síndrome de imunodeficiência adquirida; Estratégias; Cuidados de enfermagem. \section{WITH THE DISEASE}

STRATEGIES USED BY MOTHERS WHOSE CHILDREN HAVE HIV, FOR CO-EXISTING
\end{abstract}

ABSTRACT: The aim was to identify strategies used by mothers whose children have HIV, so as to co-exist with the disease. It is a qualitative study undertaken between February and March 2011 in a public hospital which is a center of excellence in care for individuals with HIV and AIDS, in Fortaleza-Ceará. Ten HIV-positive mothers with at least one child with HIV-positive serology, participated in an interview with a semi-structured script. The data was submitted to thematic content analysis, producing five categories: Adoption of religiosity as a source of hope; Strengthening of the care for the child, and over-protection; Search for family and social support; Development of self-blame; Denial of the illness and concealment of the diagnosis. The results show that the mothers find positive and negative strategies for coping with the disease. Nursing can contribute to the integration of the family members of people with HIV and provide a better quality of life, in accordance with the resources which these have to live. DESCRIPTORS: HIV; Acquired Immunodeficiency Syndrome; Strategies; Nursing care.

\section{ESTRATEGIAS DE MADRES PARA CONVIVIR CON LA ENFERMEDAD DE HIJOS CON HIV}

RESUMEN: La finalidad fue identificar estrategias de madres para convivir con hijos con HIV. Este es un estudio cualitativo desarrollado entre febrero y marzo de 2011 en un hospital público de referencia en el atendimiento de individuos con HIV y SIDA en Fortaleza, Ceará. Diez madres con HIV, con por lo menos un hijo con serología anti-HIV positiva participaron de entrevista con guión semiestructurado. Los datos fueron sometidos al análisis temático de contenido, produciéndose cinco categorías: Adopción de la religiosidad como fuente de esperanza; Aumento de los cuidados con el niño y protección exagerada; Búsqueda del apoyo familiar y social; Desarrollo de la autoculpa; Negación de la enfermedad y ocultación del diagnóstico. Los resultados muestran que las madres encuentran estrategias positivas y negativas para afrontar la enfermedad. La enfermería puede contribuir en la integración de los familiares de personas con HIV y proporcionar más cualidad de vida de acuerdo con los recursos que estes disponen para vivir. DESCRIPTORES: HIV; Síndrome de inmunodeficiencia adquirida; Estrategias; Cuidados de enfermería.

\footnotetext{
*Extraído da Monografia 'Enfrentamento e preconceitos vivenciados pelo binômio mãe e filho na vivência de HIV' apresentada ao Curso de Graduação em Enfermagem da Universidade Federal do Ceará - UFC, em 2011.

${ }^{1}$ Enfermeira. Doutora em Doenças Tropicais. Professora do Curso de Graduação e do Programa de Pós-Graduação em Enfermagem da UFC. Líder do Núcleo de Estudos em HIV/aids e Doenças Associadas - NEAIDS.

${ }^{2}$ Enfermeira. Mestre em Enfermagem. Professora do Centro Tecnológico de Educação do Ceará.

${ }^{3}$ Enfermeira. Doutora em Farmacologia. Professora do Curso de Graduação em Enfermagem da UFC.

${ }^{4}$ Enfermeira. Professora da Escola Estadual de Educação Profissional Marvin.

${ }^{5}$ Enfermeira. Professora da Escola Estadual de Ensino Profissional Onélio Porto.
}

Autor correspondente:

Marli Teresinha Gimeniz Galvão

Universidade Federal do Ceará

Rua Alexandre Baraúna, 1115 - 60430-160 - Fortaleza-CE-Brasil

E-mail:marligalvao@gmail.com
Recebido: 14/06/2012

Aprovado: 24/04/2013

Cogitare Enferm. 2013 Abr/Jun; 18(2):230-7 


\section{INTRODUÇÃO}

Desde o seu surgimento, a epidemia da Síndrome da Imunodeficiência Adquirida (aids) tem causado profundo impacto na população, constituindo um problema de saúde pública no plano nacional e mundial. Ao longo dos trinta anos da epidemia, a infecção pelo Vírus da Imunodeficiência Humana (HIV) passou de restrita a indivíduos do sexo masculino, à rápida disseminação entre o sexo feminino, culminando no nascimento de crianças expostas ao HIV e, consequentemente, famílias convivendo com até mais de um filho nascido exposto ao vírus, ou já infectado ${ }^{(1)}$.

O viver com HIV é permeado pela sobrecarga pessoal e pelo sentimento de culpa. Ademais, os portadores tendem a enfrentar carência nas relações afetivas e na sexualidade, além de problemas sociais. Isso gera sentimentos de rejeição e medo, prejudicando sua qualidade de vida ${ }^{(2)}$. Assim, preconceito, estigma e exclusão social são fatores que caracterizam a doença de forma marcante ${ }^{(3)}$.

No caso específico das mães soropositivas para o HIV, observa-se o medo de contaminação da criança e a culpa por ser portadora do vírus. Estas dificuldades podem acarretar danos psicológicos e físicos para o binômio mãe e filho ${ }^{(4)}$. Diante desse dilema, as mães podem buscar estratégias com vistas a promover a adaptação a esta realidade, bem como garantir o bem-estar da criança. Determinadas situações incentivam estas mulheres a darem continuidade à vida, mesmo em face do HIV ${ }^{(5)}$.

Devido à amplitude da infecção pelo HIV na população, além da problemática que ocasiona na vida individual, familiar e coletiva ${ }^{(6)}$, consideramos importante conhecer as formas de enfrentamento utilizadas pelas mães de filhos infectados pelo HIV. Nesse contexto, o objetivo desse estudo foi identificar as estratégias das mães que cuidam de filhos portadores de HIV para conviverem com a doença. Observações dessa natureza identificam demandas de cuidado essenciais para a promoção de assistência de enfermagem individualizada e holística. Portanto, esta pesquisa pode direcionar a assistência em saúde, representando subsídio para os profissionais que atuam nesta área.

\section{MÉTODO}

Estudo qualitativo realizado entre fevereiro e março de 2011 no ambulatório de um hospital público estadual, referência no atendimento a indivíduos com
HIV e aids em Fortaleza-Ceará.

Os critérios de inclusão das participantes foram: ser portadora de HIV, com pelo menos um filho nascido exposto ao HIV e que foi infectado pelo vírus. Foram critérios de exclusão o diagnóstico de doença mental ou qualquer outra condição mental que interferisse nas respostas aos quesitos elaborados pelo pesquisador.

As participantes do estudo foram 10 mulheres, sendo este número determinado pelo critério de saturação de dados, o qual consiste no conhecimento formado pelo pesquisador de que conseguiu compreender a lógica do grupo ou da coletividade em estudo ${ }^{(7)}$. Em consonância com os aspectos éticos, o projeto foi submetido ao Comitê de Ética em Pesquisa do hospital onde foi realizado o estudo, sendo aprovado sob Protocolo n. 035.04.10. Para preservar a identidade das participantes foram usados algarismos arábicos de acordo com a ordem de registro, antecedidos pela letra 'M' (mãe). Como determinam as normas éticas, os resultados da pesquisa foram utilizados somente com fins científicos.

As mães foram convidadas a participar da pesquisa enquanto aguardavam a consulta de acompanhamento de saúde do filho no ambulatório do hospital. Todas as participantes foram informadas quanto ao propósito do estudo e formalizaram a participação, assinando o Termo de Consentimento Livre e Esclarecido.

A coleta de dados se deu por meio da aplicação individual e em ambiente privativo, de instrumento semiestruturado, obtendo-se informações sociodemográficas, epidemiológicas e clínicas da mãe e do filho. Foram aplicadas as seguintes questões norteadoras: 'Conte-me como é o viver da senhora e do seu filho. infectado pelo HIV. Vocês vivenciam situações conflituosas? Que estratégias são utilizadas pela senhora nestas situações?'. As entrevistas foram realizadas por um pesquisador treinado, tiveram duração média de 45 minutos e foram audiogravadas.

Após a coleta dos depoimentos houve o processo de transcrição dos relatos em textos escritos, os quais foram lidos e explorados individualmente e em conjunto. Para o tratamento dos dados trabalhou-se com a análise temática de conteúdo ${ }^{(8)}$, seguindo-se as etapas: 1. Organização e sistematização das ideias; 2. Exploração do material, transformação sistemática dos dados brutos do texto, por recorte e agregação, para atingir uma representação do conteúdo e a compreensão do texto; 3 . Tratamento dos resultados, inferência e interpretação. Assim, foram analisados os depoimentos e categorizados por inferência de conteúdos semelhantes. 
Mediante a análise dos depoimentos das mães, surgiram cinco categorias para as estratégias desenvolvidas para viverem com HIV: Adoção da religiosidade como fonte de esperança; Avigoramento dos cuidados com a criança e superproteção; Busca do apoio familiar e social; Desenvolvimento da autoculpa; e Negação da doença e ocultação do diagnóstico.

\section{RESULTADOS}

A idade das mães participantes variou de 25 a 49 anos, com escolaridade predominante de ensino fundamental incompleto. Cinco referiram ser católicas e cinco evangélicas, seis referiram ser donas de casa, uma agente de saúde, uma diarista, uma auxiliar de produção e uma auxiliar de cozinha. A renda familiar informada foi igual ou inferior a um salário mínimo. Sobre os filhos portadores de HIV, seis eram do sexo masculino e quatro do feminino, com idade variando de dois a onze anos, apenas uma das crianças não frequentava a escola.

A seguir, descrevem-se as categorias apreendidas com base nos depoimentos das mulheres entrevistadas.

\section{Adoção da religiosidade como fonte de esperança}

A religião significa uma estratégia de suporte social e emocional por proporcionar esperança e coragem no enfrentamento dos problemas, conforme observado nas falas das participantes:

A gente tem o apoio da igreja, e a minha fé também ajuda. (M10)

\section{Eu peço a Deus força e coragem [...]. (M8)}

Eu peço a Deus que eu e ele não transmitamos o HIV para ninguém. É uma doença que não tem cura, que dizem que não tem cura, mas eu tenho fé em Deus que ainda vai ter cura. (M3)

Assim, as crenças religiosas tornam-se uma fortaleza para estas mulheres, uma forma de alívio na angústia. Além disso, de acordo com algumas participantes, a cura física pode ser alcançada por meio da fé.

\section{Avigoramento dos cuidados com a criança e super- proteção}

Constatou-se que para as mães o filho portador de
HIV é visto como mais frágil quando comparado com as outras crianças. Verifica-se uma maior preocupação em relação aos cuidados e restrição de atividades diárias, como descrito a seguir:

Ela estava com a imunidade muito baixa, não podia fazer muito esforço, correr, brincar, para ela não ter nenhum sangramento. Hoje em dia eu tomo mais cuidado com ela, porque ela precisa [...]. Eu tenho um cuidado maior com ela pelo fato de ela ter o que tem, não é? (M3)

Tenho mais cuidado com ele sim, eu acho que foi uma nova vida. Eu acho que ele vai ficar doente, se ele brincar mais do que os outros, correndo, ele é mais frágil. (M2)

É comum o fato de as mães terem sentimentos de superproteção e cuidados com seus filhos. Mas no caso de mães com filhos portadores de HIV há superproteção e está é caracterizada pelo cuidado em excesso, restrição de atividades cotidianas, manifestação de carinho e atenção adicionais voltadas para o filho portador do vírus em detrimento dos demais, além do isolamento da criança. As falas a seguir revelam estes aspectos:

Eu sempre acho que ele vai adoecer, assim não é prá brincar como as outras crianças, pois sempre adoece. Eu já percebi, aí eu evito. (M2)

No colégio que ela estuda, o diretor e a professora sabem, eu digo pra não deixarem ela ir para o recreio [se referindo à filha] porque eu tenho medo dela cair, se machucar e algum coleguinha tentar ajudar a limpar o sangue. Aí não vai dar certo, eu prefiro que ela fique na sala, fazendo alguma tarefa [...]. É melhor assim do que correr o risco de contaminar outro amiguinho. (M3)

[...] às vezes, ela quer ir brincar com meus sobrinhos, na casa da minha mãe, mas eu não deixo pelo medo do que vão falar, ai ela fica em casa sozinha, brinca mais é só. (M3)

Apesar dos avanços no âmbito da doença, principalmente, pelo advento dos fármacos antirretrovirais, ainda prevalece a associação da aids com a morte. Diante do HIV, a maternidade é vivenciada com dúvidas e medos, como a iminência da morte, tanto da mãe como do filho: 
[...] agora a respeito deles eu já tenho medo, porque eu fico imaginando quem vai cuidar deles se eu chegar a morrer? E ninguém vai ter o cuidado com ele como eu tenho, dar as medicações dele direito, vir para as consultas, fazer os exames. Ninguém vai ter esse cuidado. (M4)

Tenho muito medo. A coisa que eu mais tenho medo na vida é a morte, de nós duas. Dela porque eu não quero perder minha filha, e de mim porque eu tenho medo que ela fique só [...]. (M5)

No entanto, há pessoas que se habituam a conviver com o vírus. Nesse caso, o medo da morte é atenuado, e a aids passa a ser vista como uma doença crônica que, se tratada, pode ser mantida sob controle.

Eu não tenho medo da morte. Eu sou evangélica, seja o que Deus quiser. (M2)

Nãotenhomedodamorte,nemdemimnemdele[filho].(M7)

\section{Busca do apoio familiar e social}

Nesta categoria confirma-se a importância do apoio familiar e social para as pacientes, que é utilizado como uma estratégia para enfrentamento da doença:

Minha família sabe e eu tive muito apoio da minha família. Isso me deixa melhor. Minha família é um amor comigo [...]. (M6)

Minha família sabe, só não meu pai, elas me deram total apoio, e eu não me sinto desamparada, me sinto bem assim [...]. (M9)

Contudo, também são encontrados relatos de pacientes que não tiveram apoio familiar, condição evidenciada pelo distanciamento dos familiares após a revelação do diagnóstico.

[...] quando eu engravidei o pai dele não me deu apoio nenhum, fiquei abandonada [...]. (M4)

Minha mãe não aceita, não me deu nenhum apoio, assim a vida fica mais difícil para mim [...]. (M10)

Ademais, frequentemente as pessoas com HIV vivenciam o estigma social representado por situações constrangedoras, até mesmo no âmbito familiar. O preconceito dirigido aos pais estende-se às crianças. Ressalta-se a desinformação entre familiares, vizinhos e amigos no tocante às vias de transmissão do vírus. Isto constitui o estopim para o isolamento da criança, como identificado:

A minha família tem um preconceito diferente com a minha filha pelo fato de ela ser doente. Eu vejo que por ela ter o que tem [...] não é a mesma coisa, sempre quando a minha irmã vai para lá com meus outros sobrinhos, ela às vezes não deixa os meninos brincarem com minha filha, com meus outros filhos deixam, mas com ela não. (M3)

[...] tenho um irmão que é cabeleireiro. Ele deixou de cortar o cabelo do meu filho depois que soube que ele era HIV positivo [...] minha irmã também, ela tem uma menina de cinco anos e ela disse que não chegasse perto dele, se ele sentava perto dela, aí ela ia se afastando. (M7)

\section{Desenvolvimento da autoculpa}

No presente estudo, algumas mães se consideravam responsáveis pela transmissão vertical do vírus para o filho. Apesar de a profilaxia ser oferecida gratuitamente nos serviços públicos de saúde, o diagnóstico da mãe nem sempre é descoberto em tempo oportuno para a proteção da criança, ou em raros casos, as mães não são orientadas da forma correta para programarem os cuidados preventivos, como exposto a seguir:

Sinto culpa, sinto porque eu poderia ter evitado a gravidez. (M1)

Eu me senti muito culpada, no começo eu fiquei muito mal, no começo foi difícil, eu não sabia o que dizer [choro] porque se eu tivesse descoberto antes eu jamais tinha passado para ele [...]. (M9)

É comum o sentimento de autoculpabilização ou de culpabilização de outrem, seguido de afastamento do problema diante da contaminação do filho pelo HIV. Este sentimento gera conflitos internos, tais como culpa, vergonha, dor e angústia:

Eu acho que eu não devo me sentir culpada, sabe por quê? Porque eu não sabia, se eu soubesse, até no começo da gravidez mesmo, eu tinha feito o tratamento, tinha evitado, eu não tive como evitar porque nem eu mesma sabia que eu tinha aids [...]. Se eu tivesse como, tinha prevenido, mas não deu. (M3) 


\section{Negação da doença e ocultação do diagnóstico}

As participantes mostraram atitude de negação acerca da própria doença e quanto ao diagnóstico da criança. Esta foi uma estratégia para conviver com o HIV, e uma forma pela qual as mães mantinham a esperança de que poderiam ter uma vida saudável no futuro:

[...] às vezes, eu nem me lembro que eu tenho aids [...]. Tomo os antirretrovirais como se tomasse qualquer outro remédio. (M6)

Eu creio que ele [filho] está passando por isso e eu também, mas vai chegar o dia em que isso vai acabar. Eu vejo que ele está bem, está tomando a medicação regularmente [...]. Eu estou vivendo esse problema, mas tento esquecer que estou vivendo [...]. Não me preocupo tanto [em relação à criança] porque hoje em dia, o problema não é tão grave e incomum como antigamente. (M1)

Em alguns casos, o medo do preconceito é tão alarmante que as mães optam em manter sob sigilo a sorologia positiva, visto não acreditarem na existência de apoio social, além de temerem as críticas e a exclusão. O sigilo é mantido, inclusive, na escola da criança, como mostrado a seguir:

Ninguém sabe, nem na escola, só conto prá quem eu confio realmente. (M3)

Os meus vizinhos, a escola e a professora não sabem. Ninguém vai me ajudar mesmo. Não vou sair contando, ninguém vai me ajudar [...]. Eu prefiro ficar assim mesmo. (M2)

A ocultação do diagnóstico pela mãe ocorre em relação aos familiares, amigos e vizinhos, sendo também direcionada ao filho. Ou seja, ele não sabe que é portador do HIV. Esta atitude é justificada pelas mães por não saberem o momento ideal para revelar o diagnóstico ao filho. Diante da dúvida, adiam este momento. Isso é exposto a seguir:

Quando ele tiver maior eu vou explicar, quando ele estiver bem maior. (M2)

Ele [o filho] pergunta, só que eu nunca expliquei para ele não. Eu prefiro explicar assim, quando eu tiver na presença de alguma psicóloga [...]. (M4)

\section{DISCUSSÃO}

Neste estudo, que buscou identificar as estratégias das mães que cuidam de filhos portadores de HIV para conviverem com a doença, a idade das entrevistadas demonstrou que a infecção pelo vírus afeta, especialmente, as pessoas na época mais produtiva da vida, seja no que se refere à reprodução, ao trabalho e à constituição de uma família, como observado em outros estudos; além disso, constatou-se baixos níveis de escolaridade e renda ${ }^{(1-4)}$.

Diante da análise das estratégias que as mães com filhos portadores de HIV utilizam para conviverem com a doença, identificou-se que as práticas religiosas estão presentes no enfrentamento da soropositividade para o HIV e auxiliam o indivíduo a manter o equilíbrio e a esperança de um dia alcançar a cura ${ }^{(9-10)}$. A busca da religiosidade acarreta crescimento psicológico e espiritual, sobretudo, por melhorar a qualidade de vida e a resolução de problemas emocionais, proporcionando sentimentos de conforto e alívio do medo da morte ${ }^{(11-12)}$.

Os profissionais de saúde devem respeitar o posicionamento das mães diante da crença em Deus e sua religiosidade como forma de enfrentamento do HIV. Contudo, a despeito do papel da religiosidade, não se pode negligenciar o tratamento farmacológico, pois nenhuma prática religiosa o substitui.

As mães também avigoravam os cuidados em relação ao filho, às vezes, realizando superproteção. Em estudo prévio com cuidadoras de crianças com HIV, observou-se que a maioria restringia atividades capazes de facilitar a aquisição de doenças oportunistas, ou trazer danos físicos à criança, a exemplo do manuseio de objetos cortantes ${ }^{(13)}$.

Para as mães, o reforço dos cuidados com o filho funciona como uma forma de doação, uma tentativa de atenuar o fato de se sentirem culpadas pela exposição da criança ao vírus. $O$ temor da morte e o risco do filho apresentar alguma doença secundária à infecção pelo HIV levam as mães a reservarem tempo maior aos cuidados deste ${ }^{(5)}$. Algumas mães disponibilizam todo seu tempo, deixando inclusive de trabalhar para cuidar integralmente do filho, de maneira a dedicar-se ao tratamento e à prevenção de doenças oportunistas. Isso acontece em decorrência do medo da criança adoecer, de transmitir o vírus para outras crianças ou para protegê-la de situações de preconceito ${ }^{(9)}$.

Vale ressaltar que o avigoramento dos cuidados é algo saudável, desde que não prive a criança do contato sociale de atividades que lhe dão prazer. As mães devem estar atentas ao cuidado com seu filho, principalmente, 
em relação ao acompanhamento médico e ao seguimento da terapia antirretroviral. No entanto, tudo deve ser feito sem excessos, de forma a primar pelo equilíbrio. As condições ambientais do micro e macrosistema em que vive a criança e a estrutura familiar em que ela está inserida são aspectos significativos no desenvolvimento de suas potencialidades como ser-no-mundo ${ }^{(14) .}$ Assim, quando exagerada, a superproteção pode acarretar eventuais problemas comportamentais e limitações sociais, em decorrência da dependência da criança imposta pela mãe.

Muitas pacientes afirmaram o apoio da família. Segundo a literatura, esse apoio ajuda no tratamento, melhorando a qualidade de vida do portador de HIV. Contudo, também são encontrados relatos de pacientes que não tiveram apoio familiar, condição evidenciada pelo distanciamento das famílias após a revelação do diagnóstico, um achado de outros estudos ${ }^{(2,15)}$. Em pesquisas realizadas com gestantes HIV positivas observou-se que elas também não tinham apoio familiar suficiente e eram discriminadas pelos próprios familiares ${ }^{(15-16)}$.

Compete aos profissionais de saúde esclarecer dúvidas acerca das formas de transmissão do vírus, no intuito de sensibilizar os familiares sobre a importância do apoio social para a melhoria da qualidade de vida dessa clientela. A família deve inteirar-se do tratamento e aprender a ter domínio sobre os cuidados com a criança. Desse modo, poderá perceber que é possível conviver com a doença.

Como estratégia diante das situações de preconceito, muitas das mães preferem o isolamento, o que pode contribuir para a restrição de relacionamentos familiares, de modo a evitar situações constrangedoras. Estudos mostram que a vida das mulheres portadoras do HIV é repleta de angústia e rejeição social. Subjacente a esses sentimentos demonstra-se a dificuldade de viver com HIV, uma doença marcada pela discriminação ${ }^{(2-3)}$. Diante da falta de apoio familiar e social, aliada ao preconceito, torna-se mais difícil tomar decisões sobre o próprio tratamento e adaptar-se à nova vida e ao cuidado em face da soropositividade da criança ${ }^{(3)}$. O combate ao preconceito dirigido aos portadores do HIV, em especial no caso de crianças, deveria ser incentivado entre os meios de comunicação, pois a desinformação sobre as formas de transmissão do vírus predomina e está associada às situações de preconceito.

Muitas das mães se sentiam culpadas pelo diagnóstico soropositivo da criança. Nesse contexto, os serviços de saúde devem aprimorar a rotina de exames sorológicos no pré-natal, para que haja o diagnóstico precoce e redução do risco de transmissão vertical. Po- rém, apenas esta consciência por parte dos profissionais não é suficiente, é necessário que este disponha de uma rede laboratorial apta a realizar e divulgar o resultado do exame em tempo hábil ${ }^{(17)}$.

A negação da doença foi uma importante forma de enfrentamento por parte das mães soropositivas para o HIV. Conforme revelado, elas assumem esta postura quanto ao próprio diagnóstico e ao do filho que convive com o vírus ${ }^{(9)}$. A despeito de serem portadoras do vírus, às vezes, elas evitam lembrar-se deste fato, com vistas a diminuir a dor e o sofrimento. O pensamento voltado para a doença acarreta sentimentos de culpa e sofrimento, os quais podem influenciar no processo de adaptação à doença.

A negação também pode provocar isolamento social e recusa em buscar apoio social ${ }^{(12)}$. Por outro lado, a negação pode ser um fator positivo para essas mulheres, pois auxilia na continuidade do acompanhamento do binômio mãe e filho, melhorando a qualidade de vida de ambos. Muitas vezes, refere-se que a atitude de esquecer a situação vivenciada é uma estratégia benéfica para enfrentar a infecção pelo HIV ${ }^{(15)}$.

A ocultação do diagnóstico pelas mães é direcionada, principalmente, ao filho. Ou seja, ele não sabe que é portador, e também em relação aos familiares, amigos e vizinhos. As mulheres buscam estratégias para não revelarem o diagnóstico, até mesmo quando interrogadas pela criança sobre a necessidade da ingestão diária de medicamentos. Há também a troca de embalagens das medicações e acompanhamento de saúde dos filhos em outro município, para manterem o sigilo quanto ao diagnóstico da criança ${ }^{(6,9)}$.

As mães necessitam de apoio psicológico com vistas a saberem o real momento para revelarem o diagnóstico aos filhos, pois temem a reação destes. No presente estudo, nenhuma mãe havia revelado o diagnóstico ao filho. Algumas mães afirmaram que o filho era muito pequeno e não teria discernimento para compreender a soropositividade para o HIV. Segundo outras, a adolescência seria o momento ideal para revelarem o diagnóstico, no entanto, faltava-lhes preparo suficiente para realizar tal esclarecimento.

De acordo com a literatura, é evidente a preocupação das mães com seus filhos doentes ${ }^{(18-19)}$. Prevalecem sentimentos de medo de adoecer e de morrer, levando a comportamentos superprotetores $^{(9)}$. É comum o medo de não poder ver o filho crescer, de não participar ativamente do desenvolvimento da criança e desempenhar o papel de mãe ${ }^{(16)}$. Apesar da evolução na busca da cura e no tratamento da aids, a proximidade com a morte 
ainda é comum. Porém, a convivência com a doença e com outros portadores leva as mulheres a verem a aids de maneira menos trágica ${ }^{(12)}$.

Mesmo com os avanços da medicina no âmbito do tratamento da aids, esta ainda é uma doença incurável. Assim, é frequente sua associação com a morte ${ }^{(17,19)}$. Mas as mães portadoras do HIV devem ser estimuladas a realizarem o acompanhamento periódico de saúde, com vistas a ampliar sua expectativa de vida. Deve-se encorajar a reafirmação da vontade de viver e a prática de atividades agradáveis. Tais atitudes podem minimizar os sentimentos de culpa, tristeza e angústia.

\section{CONSIDERAÇÕES FINAIS}

Este estudo demonstrou que as mães de crianças portadoras de HIV encontram maneiras, tanto positivas quanto negativas, para viverem com a doença, de forma que os enfrentamentos advindos da infecção pelo HIV repercutirão diretamente no cotidiano das mães e crianças. A religiosidade, o avigoramento dos cuidados com a criança, a superproteção, a busca do apoio familiar e social, a autoculpa, a negação da doença e ocultação do diagnóstico foram estratégias utilizadas pelas mães portadoras do HIV na criação de seus filhos.

Evidenciou-se o forte estigma social vivenciado por mãe e filho, inclusive no âmbito familiar. Este achado mostra a necessidade da inserção dos companheiros e familiares no tratamento dos portadores, visto que podem contribuir para o bem-estar e melhor qualidade de vida do binômio mãe-filho.

A presente pesquisa mostra a importância da assistência de enfermagem às mães soropositivas para o HIV. São várias as formas de cuidar nesse contexto, incluindo o acolhimento na consulta de enfermagem, que pode estabelecer vínculo com o paciente, por meio do diálogo e esclarecimentos de dúvidas acerca da doença e tratamento, além da promoção de grupos terapêuticos para viabilizar a troca de experiências e apoio mútuo.

Por fim, considerando os diversos problemas que permeiam a vida dos infectados pelo HIV, ressaltamos a necessidade de mais estudos acerca desta temática, para que o profissional enfermeiro, e demais membros da equipe de saúde, possam contribuir de forma eficaz no provimento de saúde a esses indivíduos.

\section{REFERÊNCIAS}

1. Silva MJM, Mendes WS, Gama MEA, Chein MBC, Veras DS. Perfil clínico-laboratorial de crianças vivendo com HIV por transmissão vertical em uma cidade do Nordeste brasileiro. Rev. Soc. Bras. Med. Trop. 2010;43(1):32-5.

2. Carvalho CML, Galvão MTG. Enfrentamento da AIDS entre mulheres infectadas em Fortaleza CE. Rev Esc Enferm USP. 2008;42(1):90-7.

3. Seben G, Gauer GJC, Giovelli GRM, Gastal R. Adultos jovens portadores de HIV: análise dos processos subjetivos no enfrentamento da doença. Psic rev. psicol. vetor ed. 2008;9(1):63-72.

4. Galvão MTG, Cunha GH, Machado MMT. Dilemas e conflitos de ser mãe na vigência do HIV/AIDS. Rev Bras Enferm. 2010;63(3):371-6.

5. SchaurichD, Freitas HMB. Oreferencial de vulnerabilidade ao HIV/AIDS aplicado às famílias: um exercício reflexivo. Rev Esc Enferm USP. 2011;45(4):989-95.

6. Cardoso AL, Marcon SS, Waidmani MAP. O impacto da descoberta da sorologia positiva do portador de HIV/AIDS e sua família. Rev. enferm. UERJ. 2008;16(3):326-32.

7. Minayo MCS. O desafio do conhecimento: pesquisa qualitativa em saúde. 9a ed. São Paulo: Hucitec; 2006.

8. Bardin L. Análise de conteúdo. $4^{\mathrm{a}}$ ed. Lisboa: Persona; 2009.

9. Silva RAR, Rocha VM, Davim RMB, Torres GV. Formas de enfrentamento da AIDS: opinião de mães de crianças soropositivas. Rev. Latino-Am. Enfermagem. 2008;16(2):260-5.

10. Ribeiro AC, Paula CC, Neves ET, Padoin SMM. Perfil clínico de adolescentes que têm AIDS. Cogitare enferm. 2010;15(2):256-62.

11. Calvetti PU, Muller MC, Nunes MLT. Qualidade de vida e bem-estar espiritual em pessoas vivendo com HIV/AIDS. Psicol. estud. 2008;13(3):523-30.

12. Neves LAS, Gir E. Mães portadoras do HIV/AIDS: percepções acerca da severidade da infecção. Rev Esc Enferm USP. 2007;41(4):613-8.

13. Maliska ICA, Padilha MI, Vieira M, Bastiani J. Percepções e significados do diagnóstico e convívio com o HIV/AIDS. Rev. Gaúcha Enferm. 2009;30(1):85-91.

14. Freitas HMN, Backes DS, Pereira ADA, Ferreira CLL, Marchiori MRCT, Souza MHT et al. Significados que os profissionais de enfermagem atribuem ao cuidado de 
crianças institucionalizadas com AIDS. Texto Contexto Enferm. 2010;19(3):511-7.

15. Araújo MAL, Queiroz FPA, Melo SP, Silveira CB, Silva RM. Gestantes portadoras do HIV: enfrentamento e percepção de uma nova realidade. Cienc. cuid. saude. 2008;7(2):216-23.

16. Gaspar J, Reis RK, Pereira FMV, Neves LAS, Castrighini CC, Gir E. Qualidade de vida de mulheres vivendo com o HIV/AIDS de um município do interior paulista. Rev Esc Enferm USP. 2011;45(1):230-6.

17. Cardoso AL, Marcon SS, Waidmani MAP. O impacto da descoberta da sorologia positiva do portador de HIV/AIDS e sua família. Rev. enferm. UERJ. 2008;16(3):326-32.

18. Padoim SMM, Souza IEO. A compreensão do temor como modo de disposição da mulher com HIV/AIDS diante da (im)possibilidade de amamentar. Texto Contexto Enferm. 2008;17(3):510-8.

19. Freitas HMN, Backes DS, Pereira ADA, Ferreira CLL, Souza MHT, Marchiori MRCT et al. Compreendendo o ser familiar de criança com vírus da imunodeficiência humana/ síndrome da imunodeficiência adquirida pelo olhar da complexidade. Acta Paul. Enferm. 2010;23(5):597-602. 